\title{
Sin lugar en el mundo: desplazamiento \\ forzado \\ de mujeres \\ por Guadalajara
}

\section{FM4 Paso Libre}

Rafael Alonso Hernández López* José Pablo Mora Gómez **

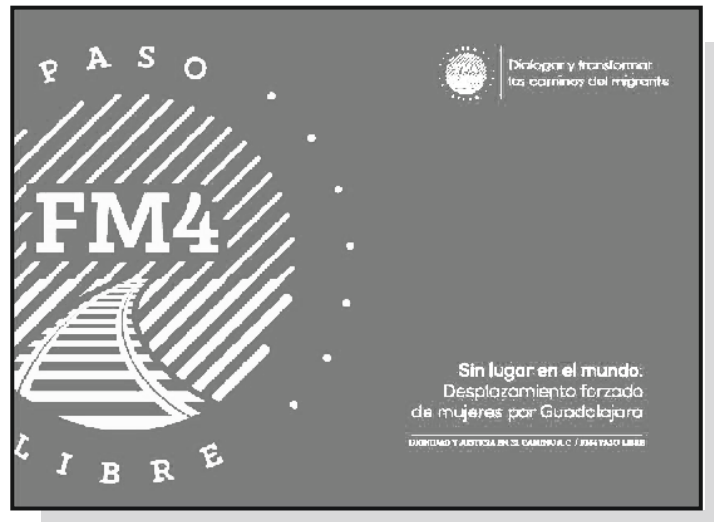

CC Que se rompan tus zapatos en el camino, no tus sueños". Esta es la frase que la madre de Clara le dijo antes de salir de su país natal y aventurarse a cruzar México para llegar a Estados Unidos. Con ella empieza también la introducción de esta obra realizada y publicada por FM4 Paso Libre. En este libro se expone y analiza la situación de las mujeres migrantes que transitan por el corredor ferroviario de occidente, que atraviesa la zona metropolitana de Guadalajara. Miles de ellas cruzan por México en búsqueda de condiciones de vida más dignas. Según los datos registrados por la Red de Documentación de las Organizaciones Defensoras de Migrantes durante los últimos tres años, el índice de mujeres migrantes ronda el 10 $\%$ de la población general que visitó las casas que conforman esta red. Del total de ellas, la mayoría eran de origen centroamericano y viajaban con destino a Estados Unidos.

En la última década el fenómeno de la migración en tránsito por México ha sido objeto de una cantidad importante de estudios, informes y diagnósticos que han buscado dar cuenta de las múltiples dinámicas que la rodean. En esos trabajos se ha abordado y caracterizado a los migrantes, sus rutas, modalidades, tiempos y condiciones de desplazamiento, así como las agresiones y violaciones a sus derechos humanos que padecen. A partir de ello se ha conocido quiénes son los hombres y las

* Doctor en ciencias sociales con especialidad en antropología por el Centro de Investigaciones y Estudios Superiores en Antropología Social de Occidente. Coordinador de Dignidad y Justicia en el Camino A.C. (FM4 Paso Libre),

* Licenciado en filosofía por el Instituto de Filosofía de Guadalajara, Jalisco. Coordinador del área de investigación de Dignidad y Justicia en el Camino A.C. (FM4 Paso Libre), investigacion@fm4pasolibre.org 
mujeres que migran; además, en qué condiciones se movilizan por nuestro país. La investigación realizada por FM4 Paso Libre se ubica en esta gama de esfuerzos que pretenden abonar a la comprensión de este complejo fenómeno.

La migración en tránsito es un fenómeno relativamente reciente en las dinámicas que se desarrollan en la zona metropolitana de Guadalajara (ZMG), pues no había sido esta una vía tan utilizada por quienes se dirigen a Estados Unidos. Pero con la presencia de los Zetas, una organización delictiva asociada al narcotráfico y la violencia implacable en el oriente de México, aquella ruta, que es la más corta en dirección a Estados Unidos, se ha convertido en la más violenta y sanguinaria, por eso los migrantes imaginan que la ruta ferroviaria de occidente o del Pacífico es más segura. La vía del tren atraviesa la ciudad de Guadalajara a lo largo de cuarenta kilómetros, por lo que se convierte en parada obligada para los migrantes que se dirigen al norte.

Para entender el carácter de la investigación publicada por FM4 Paso Libre es necesario conocer también su trabajo acompañando a personas migrantes, que inicia en el año 2007 cuando un grupo de jóvenes universitarios que habían tenido experiencias en casas del migrante en diversos puntos del país decidieron empezar a construir un proyecto de intervención en la ZMG que atendiera a las personas en tránsito. Fue así que, en mayo de 2010, se abrió el primer Centro de Atención al Migrante (CAM), en el que se ofrecía por las tardes servicio diario de comida, ropa, un espacio de aseo y descanso, así como asesoría médica básica. En julio de 2015 tuvieron que cerrar este lugar por razones de seguridad y el 26 de octubre del mismo año se abrió el nuevo Centro de Atención a Migrantes y Refugiados en otro punto de la ciudad, un espacio estratégico para quienes van en dirección al norte. El 8 de diciembre de 2016 se inauguró la sección de albergue en el CAM, con lo que inició una nueva etapa, pues ahora los migrantes podrían pernoctar en un lugar seguro, tener la ayuda humanitaria que ya recibían (tres alimentos, ropa, insumos para higiene personal, regaderas, sanitarios, llamadas a sus familias y acceso a internet), además de asesoría y acompañamiento médico, psicológico y jurídico. Esta organización combina los servicios de asistencia humanitaria con acciones de incidencia en políticas públicas y proyectos de investigación académica.

El texto que reseñamos adquiere una doble riqueza pues parte de la experiencia de acompañamiento cotidiano a personas migrantes y refugiadas, lo que refleja un compromiso de carácter social propio de un enfoque alternativo que busca incidir en la realidad de su entorno. Se complementa con los análisis de un equipo interdisciplinar de investigadores de la antropología, sociología, filosofía, psicología, comunicación pública y relaciones internacionales, de tal modo que las discusiones vertidas en el texto ofrecen una mirada amplia al fenómeno de la migración de mujeres. 
En la investigación se analiza y expone el paso de mujeres migrantes, tanto mexicanas como centroamericanas, que buscan llegar a Estados Unidos. Se combinan métodos cualitativos y cuantitativos que ayudan a entender a fondo la condición diferenciada de vulnerabilidad que enfrentan las mujeres que deciden migrar en busca de mejores condiciones de vida. Los datos presentados emanan de cuatro fuentes primordiales: una base de datos que incluye el registro de todas las mujeres atendidas por la organización desde 2010 hasta 2017, la realización de 15 entrevistas a mujeres que pasaron por el CAM entre marzo y julio de 2017, además de información obtenida de 77 entrevistas psicosociales, que se complementan con 30 entrevistas a hombres que acompañaban a mujeres durante el mismo período.

El texto está dividido en siete capítulos. En el primero se exponen las nuevas características del flujo migratorio y lo que los autores denominan feminización de las migraciones, es decir, la creciente participación de mujeres con proyectos y procesos propios de migración, característica que plantea nuevos retos para el estudio y análisis del asunto migratorio que realizan las ciencias sociales. ¿Están cambiando los paradigmas migratorios? Los autores invitan a reformular las categorías con las que se estudia el fenómeno, pues lo que antes se conocía como migración en tránsito se está convirtiendo en un proceso continuo y constante de movilidad prolongada. Las migraciones voluntarias se han convertido en forzadas por la violencia extrema que se vive en los lugares de origen. Existen movimientos incontrolados de migrantes que se encuentran en tránsito, en situaciones irregulares, refugiados y desplazados. Por eso hacen falta herramientas y conceptos que capten a los sujetos y colectivos implicados en estas movilidades en alta precariedad.

En el capítulo segundo se analiza el contexto centroamericano, procurando explicar las situaciones que obligan a las mujeres a dejar su lugar de origen. Este análisis recoge elementos económicos, políticos y sociales, y sobre todo expone el contexto de violencia que enfrentan las mujeres: las colonias rojas y la violencia intrafamiliar, el control que ejercen las pandillas en sus países y los feminicidios serían algunas de las causas de este éxodo femenino.

En el tercer apartado se delinea el perfil sociodemográfico de las mujeres atendidas por FM4 Paso Libre durante los siete años de registro. Se podrá ver que las mujeres oriundas de Honduras y México fueron las más relevantes en número durante el período de estudio. Otro dato importante tiene que ver con la edad, ya que esta organización atiende a mujeres cada vez más jóvenes, así como el estado civil, la cantidad de hijos y dependientes económicos, el nivel de escolaridad y su ocupación antes de migrar. También se expone cuáles son los estados de mayor expulsión de migrantes según el país de origen y los principales destinos, además de las causas de salida en cada país. Estos elementos permiten entender quiénes son las mujeres que han decidido emprender esta odisea. 
En el capítulo cuarto se presentan brevemente las biografías de las 15 mujeres entrevistadas. Sus historias permiten entender a profundidad los contextos de vida, y con estos las razones de sus salidas; historias marcadas por la violencia de género, los maltratos, la pobreza y las precarias condiciones en sus países de origen. Aquí se visibilizan las configuraciones de las relaciones familiares y los contextos comunitarios, escenarios propicios para el feminicidio, entornos donde se conjuntan y operan las violencias que acechan a las mujeres y a las que ellas responden forzadamente con la migración. Este capítulo sirve de antesala para el ejercicio de análisis planteado como quinto capítulo, en que los autores exhiben las condiciones en las que se desarrolla el tránsito por México y los peligros que enfrentan las migrantes.

El capítulo quinto está dividido en dos secciones, en la primera se comparan las características de las 15 mujeres entrevistadas tomando en cuenta los recursos y las capacidades de cada una y se definen cuatro perfiles de vulnerabilidad, mostrando que cada una hace frente a los riesgos del camino de modo singular y haciendo uso diferenciado de los capitales con los que cuenta. La segunda sección surge de las entrevistas realizadas a los 30 hombres; la percepción de ellos permite entender que la compañía de hombres durante el tránsito migratorio no ofrece seguridad ni protección, algunos de los entrevistados incluso aseguran que viajar con mujeres hace quela empresa se vuelva más riesgosa, lenta e insegura.

En el penúltimo capítulo se describe el impacto psicosocial que el tránsito migratorio produce en las mujeres y las notas características según la historia de vida de cada una. Aquí se sintetizan los hallazgos de las 77 entrevistas psicológicas y se visibilizan los modos en que viven la maternidad a distancia y las estrategias de acompañamiento a las que recurren durante el trayecto. Este apartado nos adentra en el mundo afectivo y sentimental de quienes han soportado cadenas continuas de violencia y los modos en los que se enfrenta. Antes y durante la travesía migratoria, la religión se presenta como un elemento fundamental para las mujeres; se convierte en un recurso no cuantificable, pero de vital importancia pues genera sentimientos de protección y acompañamiento, incluso dota de sentido e impulso en las situaciones más difíciles y complejas.

Finalmente, en el séptimo y último capítulo se dice que la feminización de las migraciones es más que un incremento en los números de mujeres mexicanas y centroamericanas que recorren el país, ellas están inmersas en complejos, multidireccionales y diversos flujos migratorios; es además un cambio cualitativo en sus objetivos, modalidades de viaje y estrategias de migración. Las mujeres visibilizan procesos graves de desvinculación del tejido social en sus lugares de origen, en el trayecto expuestas como cuerpos y mercancías en un contexto masculino y depredador. FM4 Paso Libre hace recomendaciones de políticas públicas, esto es, sugiere cambios sustantivos desligándolas de las estrategias de seguridad nacional y reubi- 
cándolas dentro de parámetros de una crisis humanitaria a la que el Estado mexicano debe atender desde sus instituciones y con sus recursos.

El libro busca visibilizar las historias de estas mujeres, sus mecanismos de afrontamiento, prácticas y luchas por sobrevivir. Al mismo tiempo, cuestiona las narrativas y los discursos académicos y oficiales, aparentemente coherentes y homogéneos, que han caracterizado a la migración "en tránsito" y en su lugar da cuenta de las diversas historias, voces y trayectorias de las mujeres como sujetos políticos, como actores de la historia que luchan por un lugar en el mundo. 